\title{
Gestão Interdisciplinar do Turismo no Planejamento Estratégico Regional: estudo de casos latino-americanos
}

\author{
Interdisciplinary Tourism Management in Regional \\ Strategic Planning: Latin American case estudies
}

\section{Geraldo Luciano Toledo ${ }^{1}$ \\ Jesús Álvarez Valdés ${ }^{2}$ \\ Álvaro Castroman Pollero ${ }^{3}$}

\begin{abstract}
RESUMO: Argumenta que, para uma gestão bem-sucedida do turismo regional, devem-se articular iniciativas de todas as entidades envolvidas, ou seja, organizações públicas, privadas e não-governamentais. A partir dessa articulação, devem ser posicionados, em um mesmo plano de gerenciamento, os objetivos das diferentes áreas de conhecimento. Assim, abordagens interdisciplinares podem ser planejadas, executadas, coordenadas e avaliadas eficientemente no âmbito do planejamento estratégico turístico regional. A metodologia adotada foi a de estudo de casos e os casos analisados referemse ao planejamento estratégico de três países: Costa Rica, México e Brasil. Os resultados revelam como são articuladas as iniciativas e objetivos do planejamento estratégico turístico e seu envolvimento com o desenvolvimento sustentável regional.
\end{abstract}

PALAVRAS-CHAVE: turismo e desenvolvimento regional; gestão regional; planejamento estratégico; Costa Rica, México e Brasil; América Latina.

1. Doutor em Administração pela Faculdade de Economia, Administração e Contabilidade (FEA) da Universidade de São Paulo. Professor titular do Departamento de Administração da FEA-USP. E-mail: gltoledo@usp.br

2. Mestre em Administração de Empresas pela Universidade de Havana, Cuba. Doutorando na área de Marketing Turístico pela FEA-USP.Professor adjunto do Centro de Estudos Turísticos da Universidade de Havana, Cuba. E-mail: jesus@usp.br

3. Doutorando na área de Turismo, Desenvolvimento Sustentável e Ordenamento Territorial pela Faculdade de Filosofia, Letras e Ciências Humanas da USP. Professor da Universidade do Uruguai (UTU).E-mail: alvarocp@usp.br 
ABSTRACT: This paper discusses the thesis that the most successful regional companies in tourism must articulate public, private and nongovernmental organizations. The articulation of these elements must fulfil in the same level of management the goals of the different areas of knowledge. In that sense, the interdisciplinary objectives can be researched, executed controlled and evaluated efficiently in the strategic planning for regional tourism. The methodological tool selected was the case study, and the three cases of strategic planning were analyzed: Costa Rica, Mexico and Brazil. The final results examined how the initiative and objectives of a strategic planning belonging to the field of tourism were articulated and their involvement with the regional sustainable development.

KEYWORDS: tourism and regional development; regional management; strategic planning; Costa Rica, Mexico and Brazil; Latin America.

\section{Introdução}

O Instituto Espanhol de Turismo (IET, 2002) define a atividade turística como um fenômeno sociológico de grande amplitude, que pode ser estudado e analisado sob várias perspectivas, integrando diferentes disciplinas ou áreas de conhecimento, como economia, ciência política, geografia, ecologia, antropologia, gestão. Podem-se obter, desta forma, definições de conceitos de turismo segundo a ótica própria de cada uma dessas disciplinas, configurando-se, assim, uma abordagem multidisciplinar. Nesse contexto, qualquer definição tende a revelar uma visão parcial do fato turístico. No entanto, algumas características da atividade turística apontam para sua complexidade e para sua natureza interdisciplinar e sistêmica. Tais características dizem respeito aos seguintes fatores presentes nas atividades turísticas: intangibilidade, perecibilidade, simultaneidade do binômio produção-consumo e demanda flutuante (Beni, 2000).

Yázigi (2001) nota duas características intrínsecas ao turismo: a primeira corresponde ao que ele define como a "arte de agradar", e a segunda remete ao pressuposto de que a atividade turística pode autodestruir-se com sua própria execução. Essas propriedades da atividade turística servem de alerta para a complexidade e o cuidado que se deve ter ao se planejar e desenvolver o sistema turístico.

Para analisar a questão do planejamento estratégico $(\mathrm{PE})$, normalmente se divide o sistema turístico em três subsistemas: o meio ambiente (MA), o trabalho $(\mathrm{T})$, como indicador do meio social, e a economia (E), configurando-se, assim, a tríade MATE. A alta inter-relação desses elementos da tríade MATE, junto com a complexidade e explosão do setor turístico na América Latina, resulta no fato de que empresários, governantes, ONGs e academia não possuem uma posição devidamente questionadora e analítica sobre o fenômeno turismo. Alguns manifestam uma atitude apologética, e outros assumem um posicionamento mais crítico, argumentando que a "indústria" do turismo "transforma tudo o que toca em artificial".

Em face dessa realidade antagônica, presente na sociedade latino-americana, neste trabalho se propõe analisar situações indicativas das inter-relações que envolvem o turismo, e realçar seus impactos regionais na tríade MATE. Especificamente, tem-se os seguintes objetivos:

- apresentar evidências práticas de como, a partir de um PE consistente, o fenômeno turístico pode contribuir como elemento de articulação do desenvolvimento sustentável (DS) regional;

- sugerir algumas atividades práticas do planejamento regional da tríade MATE para a obtenção do DS.

Do ponto de vista metodológico, o estudo apresenta-se como de caráter exploratório-descritivo, com o recurso do estudo de casos, conforme descrito por Yin (2001).

Procurou-se estudar especificamente o PE de três regiões turísticas: México, Costa Rica e Nordeste brasileiro. Para a coleta de dados, foram utilizadas entrevistas com questōes semi-estruturadas e não disfarçadas, as quais foram sendo ajustadas segundo as especificidades dos pólos turísticos estudados.

Com base na bibliografia e na opinião de técnicos responsáveis e integrantes de ONGs regionais, avalia-se como é tratada, aprimorada e articulada a idéia de desenvolvimento sustentável a partir da atividade turística, no âmbito das regiōes geográficas latino-americanas. Teve-se especial cuidado, no marco teórico deste estudo, na utilização de conceitos presentes nos relatórios das megaconferências mundiais, como o Nosso Futuro Comum, da Comissão Mundial sobre Meio Ambiente e Desenvolvimento (CMMAD - 1991), e a Agenda 21, da Conferência das Nações Unidas sobre o Meio Ambiente e o Desenvolvimento (CNUMA - Rio 92).

\section{Desenvolvimento Sustentável no Âmbito Institucional}

A Comissão Mundial sobre Meio Ambiente e Desenvolvimento (CMMAD) apresentou o relatório Nosso Futuro Comum (1991), permitindo difundir mundialmente o conceito de desenvolvimento sustentável, utilizado com o fim de inte- 
grar conceitos aparentemente discrepantes: o desenvolvimento social como ponto de equilíbrio entre ecologia e economia. O propósito era integrar os objetivos da tríade MATE em um único plano, mediante a utilização de indicadores precisos e relacionados entre si.

$\mathrm{Na}$ atualidade, uma das falhas normalmente apontadas com relação aos projetos de planejamento é o fato de que a economia se utiliza de indicadores econômicos, a área social de parâmetros sociais, e os profissionais ligados a questões de meio ambiente de termos físico-químico-biológicos. Os objetivos apresentados, segundo a perspectiva de cada um dos profissionais, revelam diferentes dimensões, sendo, portanto, problemático o estabelecimento de indicadores quantitativos universais, além de não se dispor de parâmetros comparáveis. O DS depende desta articulação de objetivos no âmbito do marco institucional.

Pode-se aproximar uma representação do DS por uma função g, que otimize e controle os objetivos comuns da tríade MATE em um mesmo plano ou dimensão:

$$
D S=g_{\text {de objetivo comuns }} \text { (Meio Ambiente, Trabalho, Economia). }
$$

Certamente, a equação não é tão trivial. Como analisa Sen (1996), para um DS de um país ou região, os três componentes da tríade são influenciados por múltiplos fatores, principalmente pela capacidade de ação conjunta e coordenada entre o governo e a iniciativa privada, baseada numa cidadania participativa. Essa coordenação é orientada por processos relacionados com educação, inovação tecnológica e formação de recursos humanos capacitados, o que é equivalente à implementação de um processo contínuo e auto-sustentável do incremento da capacidade de aprender.

\section{Desenvolvimento Sustentável e Turismo}

Segundo Paloucci (2000), em turismo, o conceito de sustentabilidade deve contemplar quatro desafios-chave:

- melhor compreensão de como os turistas avaliam e usam os ambientes naturais;

- aumento e impactos da dependência de comunidades em relação ao turismo;

- identificação dos impactos sociais e ambientais do turismo;

- implementação de sistemas para administrar estes impactos.
O crescimento econômico com alta desigualdade social não é desenvolvimento regional. Toledo et al. (2002) interpretam o porquê da preocupação do turismo com o desenvolvimento sustentável, principalmente porque na América Latina, entre outros aspectos, o turismo exige uma série de transformações socioespaciais no local original, gerando, na maioria das vezes, um impacto irreparável no meio ambiente e na sociedade anfitriã. Tais impactos fizeram Krippendorf (1977) considerar os turistas como "devoradores de paisagens", e Yázigi (2001) a chamá-los de "novos vândalos", por causa das más práticas e da falta de consciência sobre os desequilíbrios que seu comportamento consumista causa ao meio ambiente e à sociedade anfitriã. Sachs (1993) salienta a utilidade $\mathrm{e}$ capacidade do turismo de poder colocar o social no centro do desenvolvimento, isto é, de reafirmar a finalidade social do desenvolvimento.

Como potencializador econômico regional, tanto a Embratur (2002), como a Sectur (2002) são contundentes, ao apontarem a quantidade de subsetores econômicos que o turismo dinamiza. A cifra relativa a esses subsetores ultrapassa 50.

Conforme proposto no presente trabalho, considera-se a otimização da tríade MATE para o DS como a área superposta hachurada (Figura 1).

\section{Figura 1 Tríade MATE e sua otimização.}

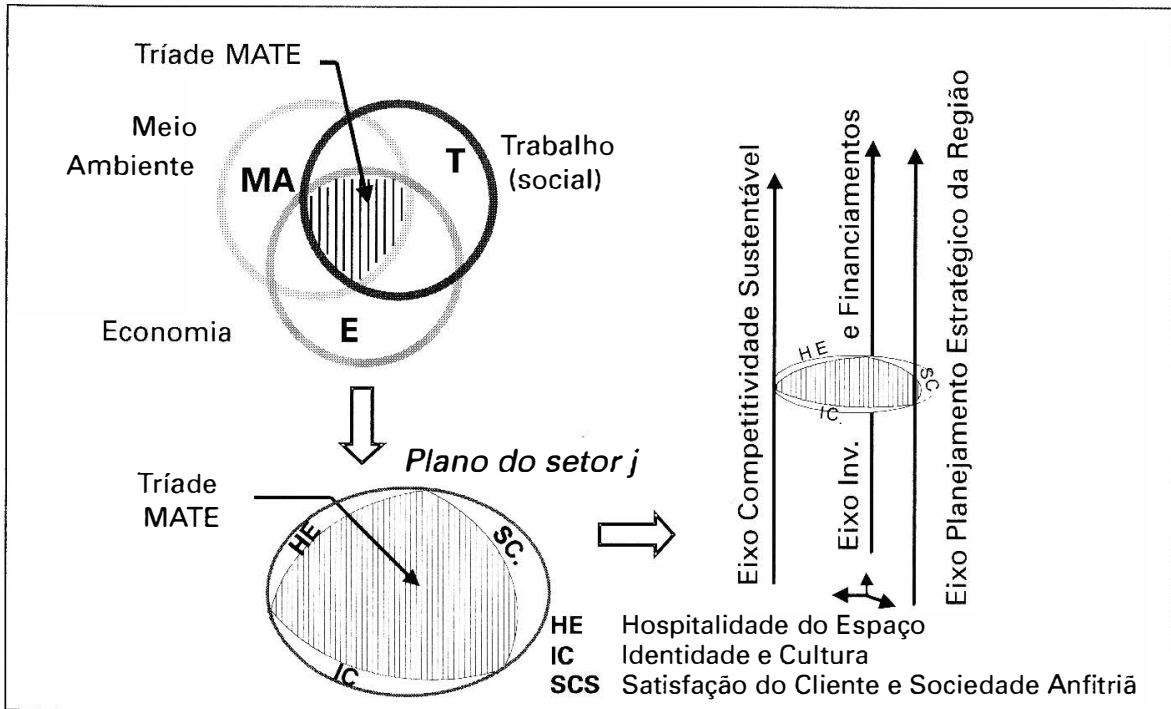

Fonte: autores. 
Nessa área, situados em um mesmo plano, encontram-se os objetivos propostos no PE da MATE e delineados para cada setor econômico i. O PE, desenvolvido de forma interdisciplinar e integrada, permite a otimização dos resultados do ponto de vista do DS. Figurativamente, esse fato revela-se no aumento da área tracejada. Como conseqüência, ocorrerá o aumento nos resultados, em termos das variáveis setoriais do DS, representadas pelas áreas em branco do círculo inferior da Figura 1: hospitalidade do espaço (HE), identidade e cultura (IC) e satisfação do cliente e sociedade anfitriã (SCS).

A maximização dessa área é o resultado da posição ocupada por três pontos, os quais aparecem na figura como as extremidades das três calotas relativas às citadas áreas em branco. Por esses três pontos passam os eixos referentes às diretrizes regionais:

- investimentos e financiamentos da região turística;

- estratégia competitiva sustentável;

- planejamento estratégico da região turística.

Na Figura 2, os três eixos referidos acima também coordenam os outros setores da atividade turística. $\mathrm{O}$ alinhamento e crescimento (tanto horizontal quanto vertical) dos setores dar-se-ão conjunta e simultaneamente. É importante notar que, ao aumentar a área da tríade MATE, geometricamente representada pelo aumento da distância entre os eixos planejamento, competitividade e financiamento, aumenta simultaneamente o DS regional.

Em sua estada, o turista vai utilizar e circular dentro da rede de fluxos coordenados por esses setores, os quais estarão integrados, geridos e orientados para a satisfação diferenciada do mesmo.

O modelo proposto permite trabalhar melhor o valor a ser agregado à marca do pólo turístico, possibilitado pela sinergia de cada um dos setores econômicos, os quais contribuem para o ciclo turístico, para a comunidade anfitriã e, conseqüentemente, para o DS.

\section{Estudo de Casos}

Neste estudo foram analisadas as políticas de desenvolvimento e de planejamento turístico, avaliando-se a tríade MATE. O objeto de estudo foram os próprios planos elaborados pelos planejamentos nas diferentes regiões latino-americanas estudadas. A cifras permitem considerar a atividade em sua dimensão real no contexto socioeconộmico dos países considerados, como mostra a Tabela 1.
Figura 2 Otimização da MATE para uma região turística.

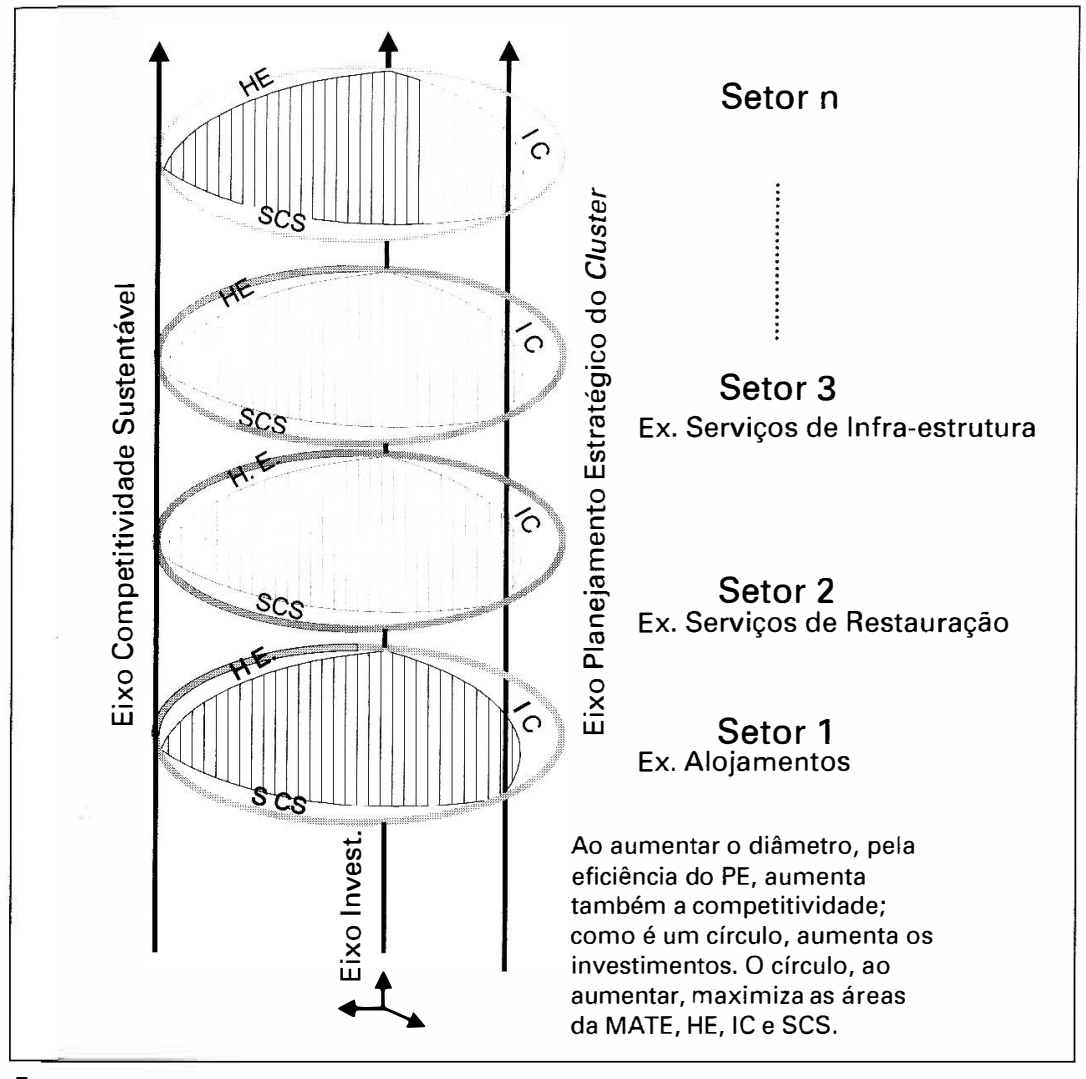

Fonte: autores.

\section{Caso México}

O país possui o plano Política e Estratégia Nacional para o Desenvolvimento Turístico Sustentável, que é o resultado da atuação da Secretaria de Turismo (Sectur, 2002) e do esforço de várias instituições dos setores público, social e acadêmico para definir as diretrizes, políticas e uma estratégia específica, de modo a criar bases para transformar a estrutura de desenvolvimento do setor e permitir $o$ trânsito até a sustentabilidade.

Para conseguir atingir os resultados, a Sectur (2002) considerou um modelo participativo de planejamento, que permitiu que os atores sociais do turismo realizassem contribuições importantes tanto em nível teórico quanto prático. 
Tabela 1 Destinos turísticos do mundo (perspectiva para o ano 2001).

\begin{tabular}{|c|c|c|c|c|c|}
\hline Turismo & Mundial & $\begin{array}{l}\text { América } \\
\text { Latina }\end{array}$ & México & $\begin{array}{l}\text { Costa } \\
\text { Rica }\end{array}$ & Brasi \\
\hline $\begin{array}{l}\text { Faturamento** } \\
\text { (\% do PIB) }\end{array}$ & $\begin{array}{c}4500 \\
(4,0 \%)\end{array}$ & $\begin{array}{c}145 \\
(3,5 \%)\end{array}$ & $\begin{array}{c}71 \\
(8,2 \%)\end{array}$ & $\begin{array}{c}3,2 \\
(7,9 \%)\end{array}$ & $\begin{array}{r}58,2 \\
(7,5 \%\end{array}$ \\
\hline $\begin{array}{l}\text { Impostos** } \\
\text { (\% do total) }\end{array}$ & $\begin{array}{c}792,4 \\
(4,2 \%)\end{array}$ & $\begin{array}{l}(-) \\
(-)\end{array}$ & $\begin{array}{l}(-) \\
(-)\end{array}$ & $\begin{array}{l}(-) \\
(-)\end{array}$ & $(-)$ \\
\hline $\begin{array}{l}\text { Empregos gerados* } \\
\text { (\% do total) }\end{array}$ & $\begin{array}{c}207 \\
(9,0 \%)\end{array}$ & $\begin{array}{c}12,7 \\
(8,5 \%)\end{array}$ & $\begin{array}{c}2,7 \\
(8,3 \%)\end{array}$ & $\begin{array}{l}0,235 \\
(16 \%)\end{array}$ & $\begin{array}{r}5,382 \\
(7,5 \%)\end{array}$ \\
\hline $\begin{array}{l}\text { Chegadas de turistas* } \\
\text { (\% do total) }\end{array}$ & $\begin{array}{c}656,9 \\
(-)\end{array}$ & $\begin{array}{c}40 \\
(6,1 \%)\end{array}$ & $\begin{array}{c}20 \\
(3,1 \%)\end{array}$ & $\begin{array}{c}2,3 \\
(0,4 \%)\end{array}$ & $\begin{array}{r}5,1 \\
10,8 \%\end{array}$ \\
\hline $\begin{array}{l}\text { Ingresso de divisas** } \\
\text { (\% do total) }\end{array}$ & $\begin{array}{c}1063 \\
(12,8 \%)\end{array}$ & $\begin{array}{c}30 \\
(12,3 \%)\end{array}$ & $\begin{array}{c}19,5 \\
(14 \%)\end{array}$ & $\begin{array}{c}1,4 \\
(18 \%)\end{array}$ & $\begin{array}{c}8,0 \\
(10 \%)\end{array}$ \\
\hline $\begin{array}{l}\text { Investimentos } \\
\text { (\% do total) }\end{array}$ & $\begin{array}{l}656 \\
(9 \%)\end{array}$ & $\begin{array}{c}22 \\
(7,8 \%)\end{array}$ & $\begin{array}{c}16,1 \\
(12 \%)\end{array}$ & $\begin{array}{l}0,580 \\
(20 \%)\end{array}$ & $\begin{array}{r}8,5 \\
16,2 \%\end{array}$ \\
\hline
\end{tabular}

* milhōes **bilhōes de U\$S

Fonte: World Travel and Tourism Council WTTC (2001).

A Sectur (2002) elaborou suas metas de acordo com a Declaração do Rio 92 e as consideraçōes da Agenda XXI para Viagens e Turismo da OMT. Após a avaliação do PE realizado pela Sectur, no período de 1995-2000, desenvolveu-se o Plano Nacional do Desenvolvimento 2000-2005, que começa com uma introdução, antecedentes e, posteriormente, apresenta as fases a serem seguidas por este, conforme pode ser observado na Figura 3.

\section{Caso Costa Rica}

As diretrizes políticas da Costa Rica estruturam-se como um aglomerado turístico que abarca todo o seu espaço nacional. Para Segura e Inman (1998), a Costa Rica encontra-se na etapa de desenvolvimento e com a experiência de vários planejamentos, execuções, mensurações e avaliações de planos anteriores, que permitem uma retroalimentação positiva dos novos planos. Em sua experiência prática, essa região tem conseguido resolver situaçōes de risco para sua sobrevivência.

O Departamento de Recursos Naturais do Instituto Costarriquense de Turismo (ICT, 2002) tem elaborado o programa "Certificação da Sustentabilidade
Figura 3 Modelo do processo mexicano de planejamento participativo (2000-2005).

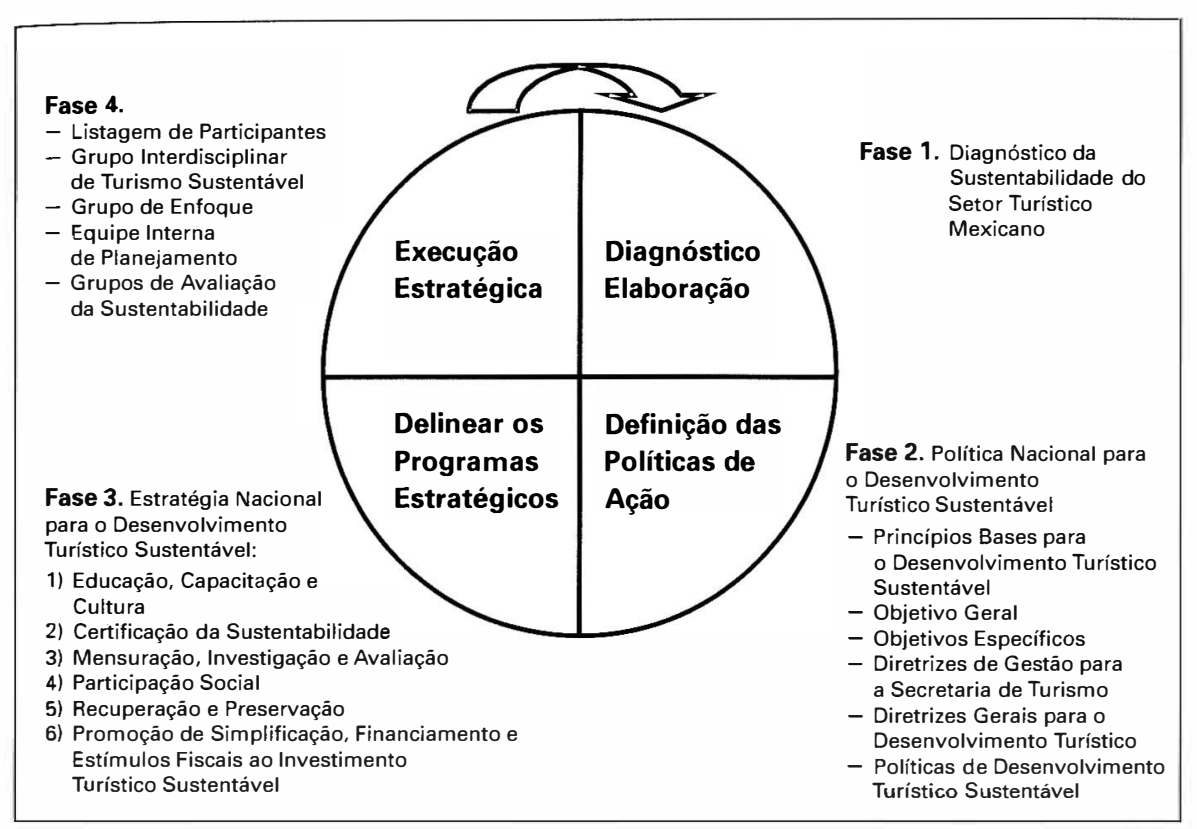

Fonte: Sectur (2002).

Turística" (CST), como estratégia para transformar o conceito de sustentabilidade em algo real, prático e necessário no contexto da competitividade turística do cluster. Tem como objetivo melhorar a forma com que se utilizam os recursos naturais e sócio-histórico-culturais. Incentiva-se a participação ativa das comunidades locais nas redes de conhecimento turístico do setor público-privado.

Com o turismo, as províncias menos ricas da Costa Rica, como Puntarenas e Guanacaste, têm encontrado um motor de desenvolvimento socioeconômico. O ICT (2002) destaca que a inclusão dos elementos socioecológicos no PE beneficia mais de 700 mil pessoas, que, direta ou indiretamente, dependem dele. Isso significa $20 \%$ do total da população do país.

\section{Caso Nordeste Brasileiro}

O Governo Federal do Brasil e o Banco Interamericano de Desenvolvimento (BID) estão apoiando a execução do projeto "Iniciativa pelo Nordeste", o qual 
visa a promover uma nova cultura para o desenvolvimento da região, a partir da formação de clusters turísticos. Nasce, assim, o Prodetur/NE, um programa que reúne um conjunto de aproximadamente 450 projetos, mobilizando recursos da ordem de US $\$ 800$ milhões, dos quais US $\$ 400$ milhões são financiados pelo Banco do Nordeste, com repasse do BID. E espera-se que sejam alcançadas as seguintes metas:

\section{Tabela 2 Parcial do ano de 1999 do executado pela Prodetur.}

\begin{tabular}{lccccc}
\hline Descrição (\% US\$ do total gasto) & Unid. & Globais & Realizados & $\%$ \\
\hline Empregos diretos & unid. & 1.687 .000 & 1.119 .215 & 66,3 \\
\hline Empregos indiretos & unid. & 2.183 .000 & 1.448 .277 & 66,3 \\
\hline Saneamento, água potável $(26,2 \%)$ & mil hab. & 809,1 & 647,0 & 80,0 \\
\hline Melhoria rede víária $(17,7 \%)$ & $\mathrm{km}$ & 647,4 & 642,1 & 99,2 \\
\hline Patrimônio histórico $(7,3 \%)$ & $\mathrm{m}^{2}$ & $287.792,7$ & $287.492,7$ & 99,9 \\
Meio ambiente $(3,1 \%)$ & $\mathrm{ha}$ & 47.679 & $44.024,4$ & 92,3 \\
\hline 8 aeroportos $(25 \%)$ & unid. & 08 & 07 & 87,5 \\
\hline Desenvolvimento Institucional $(3,7 \%)$ & projeto & 172,0 & 74,0 & 43,0 \\
\hline
\end{tabular}

Fonte: The Pro-Northeast Initiative (2000).

$\mathrm{Na}$ concepção do projeto, o setor privado é instado a mobilizar sinergias a partir de vantagens comparativas locais, para alavancar a competitividade dinâmica regional. De acordo com a Organização Mundial do Turismo (OMT, 2002), cada US $\$ 7$ mil deixados no País repercutem na manutenção de um emprego. Enquanto que na indústria automobilística são necessários $\mathrm{R} \$ 170$ mil para gerar um emprego, no turismo apenas $\mathrm{R} \$ 40$ mil possibilitam um emprego direto num hotel; $\mathrm{R} \$ 10$ mil empregam uma pessoa num restaurante e $\mathrm{R} \$ 50$ podem garantir matéria-prima e emprego a um artesão.

\section{Interpretação dos dados das três regiões}

$\mathrm{Na}$ análise das evidências práticas, pelo método das "proposições teóricas" (Yin, 2001) desenvolvidas no marco referencial para os casos deste trabalho, verifica-se que, na atual fase da implementação das teorias do DS, existe uma combinação entre arte e ciência. Isso em virtude da falta de metodologias ou indicadores comuns para áreas como Ecologia, Sociologia, Antropologia e Economia.
É um bom exemplo para outros setores a consciência do PE turístico do México e da Costa Rica, que têm começado a incorporar a dimensão ambiental, cultural e a identidade do lugar na tomada de decisões de seus processos de planejamento e fixação de objetivo. Maior destaque merece, ainda, o fato de que ambos têm obtido retorno no crescimento econômico-turístico em médio e curto prazos.

Outro aspecto em favor da otimização da tríade MATE, praticada pelas três regiões no $\mathrm{PE}$, consiste em possibilitar a identificação dos problemas, dos atores e dos métodos para resolver objetivos em comum, sejam eles públicos, privados, nacionais ou internacionais.

Além da já conhecida densidade de equipamentos, serviços, infra-estrutura, imagem e turistas necessários para a execução do turismo, os técnicos e acadêmicos dessas regiões turísticas evidenciam, nos $\mathrm{PE}$, a necessidade de articular as atividades da tríade MATE para o desenvolvimento, como pode ser observado na Tabela 3.

Tabela 3 Atividades da tríade MATE mencionadas dentro dos planos turísticos.

\begin{tabular}{|c|c|c|c|}
\hline Atividade/Pais & México & Costa Rica & Brasil \\
\hline Imagem turística & Diferenciada & Diferenciada & $\begin{array}{c}\text { Pouco } \\
\text { Diferenciada }\end{array}$ \\
\hline $\begin{array}{l}\text { Imagem turistica relacionada com a } \\
\text { identidade e cultura regional }\end{array}$ & $\begin{array}{l}\text { Altamente } \\
\text { Diferenciada }\end{array}$ & $\begin{array}{l}\text { Pouco } \\
\text { Diferenciada }\end{array}$ & $\begin{array}{l}\text { Altamente } \\
\text { Diferenciada }\end{array}$ \\
\hline $\begin{array}{l}\text { Imagem turística relacionada com o meio } \\
\text { ambiente regional }\end{array}$ & $\begin{array}{l}\text { Altamente } \\
\text { Diferenciada }\end{array}$ & $\begin{array}{l}\text { Altamente } \\
\text { Diferenciada }\end{array}$ & $\begin{array}{c}\text { Pouco } \\
\text { Diferenciada }\end{array}$ \\
\hline Planejamento participativo e capacitado & Alto & Alto & Baixo \\
\hline Sinergia da Iniciativa Pública-Privada-ONG & Média & Alta & Média \\
\hline Enfoque intersetorial, a longo prazo & Alto & Alto & Médio \\
\hline $\begin{array}{l}\text { Incentivar e facilitar os investimentos } \\
\text { sustentáveis }\end{array}$ & Definidos & Definidos & $\begin{array}{c}\text { Pouco } \\
\text { definidos }\end{array}$ \\
\hline Enfoque na competitividade global & Alto & Alto & Alto \\
\hline $\begin{array}{l}\text { Informaçōes e capacitaçāo de } \\
\text { sustentabilidade aos turistas, agentes de } \\
\text { viagens, hotéis, restaurantes, entre outros. } \\
\text { Etiqueta ecológica. }\end{array}$ & Alta & Alta & Baixa \\
\hline Sistema de gestão articulado e intersetorial & Alto & Alto & Baixo \\
\hline $\begin{array}{l}\text { Tratamento científico, literatura } \\
\text { especializada, escolas de turismo }\end{array}$ & Alto & Médio & Baixo \\
\hline Capacitaçāo de recursos humanos & Alta & Alta & Inicial \\
\hline Indicadores de sustentabilidade & Alto & Médio & Baixo \\
\hline Enfoque no consumo sustentável & Médio & Alto & Baixo \\
\hline Limites da capacidade máxima turística & Definidos & Definidos & Nāo definidos \\
\hline $\begin{array}{l}\text { Mensuração, investigação, controle, avaliação } \\
\text { dentro do planejamento }\end{array}$ & Definidos & Definidos & $\begin{array}{c}\text { Pouco } \\
\text { definidos }\end{array}$ \\
\hline Indicadores e manejo ecológico & Alto & Alto & Baixo \\
\hline Certificação ecológica & Média & Alta & Baixa \\
\hline Recuperação e preservação ecológica & Inicial & Alta & Baixa \\
\hline Retroalimentação dos planejamentos & Alta & Alta & Baixa \\
\hline
\end{tabular}


A seguir são apresentados alguns comentários sobre os países analisados, segundo as fases em que se encontram no ciclo de vida do turismo.

\section{México (Fase de Sustentabilidade)}

Com referência ao planejamento turístico desse país, salientam-se os seguintes aspectos:

- planejamento e gestão do turismo de forma sustentável, procurando otimizar as áreas da tríade MATE, considerando-se os objetivos e alguns indicadores comuns;

- inclusão, nos planos, da filosofia dos relatórios da CMMAD (1991) e da ECO 92;

- alta capacidade de articular o turismo com os demais setores;

- uso de métodos de desenvolvimento que apontam para uma distribuição mais eqüitativa de seus resultados econômicos;

- inclusão da identidade e cultura regionais para aumentar a competitividade do turismo nessa fase de turismo globalizado.

\section{Costa Rica (Fase de Desenvolvimento)}

A proposta original da Costa Rica apresenta as seguintes características:

- turismo ecológico sustentável, que utiliza, de forma competitiva, seus recursos naturais turísticos (viabilidade prática do binômio competitividade-sustentabilidade), alimentado pela inovação no manejo ambiental;

- considera métodos e indicadores com objetivos comuns à tríade MATE, como a certificação da sustentabilidade turística, possuindo etiquetas ecológicas;

- evidencia um alto grau de comprometimento e planejamento, em longo prazo, do poder público em sinergia com a iniciativa privada e outros integrantes do cluster.

Os resultados da Costa Rica são excelente exemplo para mostrar que a maior parte da responsabilidade pela degradação do turismo é conseqüência do inexistente ou ineficaz planejamento/execução, com a participação real e capacitada das sociedades anfitriās.

\section{Nordeste do Brasil (Fase de Iniciação)}

Dada a situação socioeconômica do Nordeste brasileiro, a Prodetur/NE está sendo importante em virtude dos seguintes elementos:

- ser um programa de desenvolvimento por meio de projetos;

- determinar a situação-problema, atores envolvidos, objetivos e modelo de gestão para articular o DS;

- facilitar os financiamentos e vias de investimentos nacionais e internacionais, por meio de uma articulação do poder político com a iniciativa privada.

Quanto maior for a inclusão de atividades como IC, HE, SCS (objetivos da MATE em um mesmo plano, pelo planejamento intersetorial), maior será a fase de desenvolvimento alcançada. Quatro enfoques podem ser considerados:

- mesmo com planejamento, o turismo pode ser um agente de degradação. Mas, nos casos de planejamento bem desenvolvido, uma solução de sucesso pode ser alcançada. Isso porque a atividade turística deve estar continuamente submetida a um processo de mensuração, controle e avaliação, o qual possibilita, nos casos em que seja detectada a degradação, imediata intervençāo mediante açōes corretivas, permitindo a construção da sustentabilidade da atividade turística;

- nos casos estudados, as cifras são contundentes em relação à real importância do turismo na economia nacional. Apresentam-se dados:

- proporcionar a geração de empregos diretos (aproximadamente de $8 \%$ a $10 \%)$;

- gerar divisas (aproximadamente $8 \%$ a $15 \%$ da balança nacional);

- contribuir para o PIB (entre 5\% e 9\% do PIB nacional), numa real articulação do turismo com inúmeros setores econômicos e sociais das regiōes onde se realiza (no Brasil foram diagnosticados 52 setores);

- a real capacidade de ser condutor de um DS, pela alta capacitação técnica dos responsáveis pelo planejamento. Eles possuem um enfoque sistêmico para poder articular a tríade MATE com as variáveis IC, SCS, HE, que, em outros setores, são difíceis de se encontrar;

- os processos espaciais decorrentes de um planejamento "teórico", a partir de experiências anteriores, a filosofia e a terminologia dos conceitos 
presentes em relatórios como o do CMMAD (1991) e da ECO 92 são explicitamente mencionados nos planos, embora tenham como primeiro objetivo o binômio competitividade e sustentabilidade.

\section{Considerações Finais}

Os resultados indicam que, para melhor convivência do setor turístico com a dinâmica espacial da região, deve-se estabelecer PE eficazes e promover uma gestão participativa que otimize as inter-relaçōes concernentes à tríade MATE, que deve ser concebida a partir de uma afirmação positiva da identidade e da cultura regionais.

É prioritário realizar um estudo de caráter interdisciplinar e participativo, a partir da cultura e da identidade locais, cujo resultado confirme a viabilidade econômica, sociocultural e ambiental da execução da atividade turística em uma determinada regiāo. A otimização da articulação dos objetivos, dos diferentes atores - públicos e privados - nos diferentes setores econômicos é facilitada pela capacidade metodológica do PE turístico.

Ao mesmo tempo, faz-se necessário encontrar formas de distribuir, de maneira mais eqüitativa, os benefícios do turismo e de seu próprio desenvolvimento, para elevar a qualidade de vida da população local, especialmente a dos mais carentes. Assim, com parte da sociedade inserida no fenômeno turístico e com melhor distribuição de renda, fomenta-se a construção de um ciclo sustentável do desenvolvimento. Procura-se evitar a repetição da matriz de crescimento econômico com alta desigualdade social tão intrínseca à América Latina. Dessa forma, o turismo passa a ocupar uma posição responsável, em que o setor possa articular e proporcionar o desenvolvimento sustentável regional.

\section{Referências Bibliográficas}

BENI, M. C. 2000. Análise estrutural do turismo. São Paulo: Senac.

COMISSÃO MUNDIAL SOBRE MEIO AMBIENTE E DESENVOLVIMENTO. 1991. Nosso Futuro Comum. Rio de Janeiro: Fundação Getulio Vargas.

INSTITUTO BRASILEIRO DE TURISMO (EMBRATUR). 2002.Turismo, estruturação e legislação. Rio de Janeiro: Embratur.

INSTITUTO COSTARRIQUENSE DE TURISMO (ICT). 2002. Planificación del turismo. Costa Rica: ICT.
INSTITUTO ESPAÑOL DE TURISMO (IET). 2002. Empleo y turismo. Madrid: IET. KRIPPENDORF, J. 1977. Les devorateurs de paysages. Lausanne: Heures.

ORGANIZAÇÃO MUNDIAL DO TURISMO (OMT). 2002. Compendio de estadisticas del turismo. Madrid: OMT.

PALOUCCI, L. 2000. Competitividade sustentável em turismo. Dissertação (Mestrado em Ciências da Comunicação) - Escola de Comunicaçōes e Artes, Universidade de São Paulo.

SACHS, I. 1993. Estratégias de transição para o século XXI: desenvolvimento e meio ambiente. São Paulo: Studio Nobel.

SECRETARÍA DE TURISMO DE MÉXICO (SECTUR). 2002. La politica y estrategia nacional para el desarrollo turistico sustentable. México: Sectur.

SEGURA, G.; INMAN C. 1998. Turismo en Costa Rica. Costa Rica: CLACDS.

SEN, A. 1996. Desenvolvimento como liberdade. São Paulo: Companhia das Letras.

TOLEDO, G. L. et al. 2002. Planificación estratégica de empresas turísticas. Propuesta de un modelo. Estudios y Perspectivas en Turismo, Buenos Aires.

WORLD TRAVEL AND TOURISM COUNCIL (WTTC). 2001. Tourism satellite accounting research. Canada: WTTC.

YÁZIGI, E. 2001. A alma do lugar. São Paulo: Contexto.

YIN, R. 2001. Estudo de caso: planejamento e métodos. POA: Bookman.

Recebido em 15/08/2002

Aprovado em 10/12/2002 